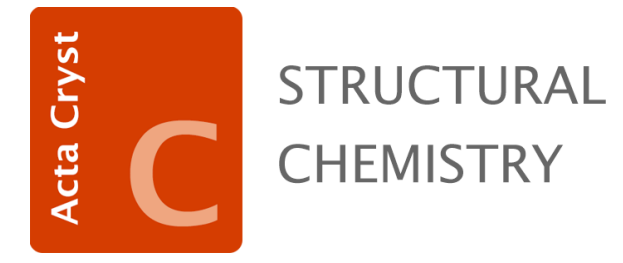

Volume 75 (2019)

Supporting information for article:

Coordination polymers of $\mathrm{Cd}^{\text {" }}$ and $\mathrm{Pb}^{\text {"l }}$ with croconate show remarkable differences in coordination patterns: a structural and spectroscopic study

Joshua A. Silverman, Logesh Mathivathanan, Evgen V. Govor, Raphael G. Raptis and Konstantinos Kavallieratos 
1. UV-Vis titrations:

The binding curves for titrations of $\mathrm{Na}_{2} \mathrm{C}_{5} \mathrm{O}_{5}$ with $\mathrm{Pb}\left(\mathrm{NO}_{3}\right)_{2}$ or $\mathrm{Cd}\left(\mathrm{NO}_{3}\right)_{2} \cdot 4 \mathrm{H}_{2} \mathrm{O}$ in $1: 1$ water:ethanol are shown in Figures S1 and S2. The binding constant for 1-1 complex formation was determined by non-linear regression analysis of the 1-1 binding isotherm. The data were fitted according to the 1-1 binding isotherm (Eq. 1) using non-linear regression methods:

$$
\left.\Delta \mathrm{A}=\mathrm{A}_{\text {obs }}-\mathrm{A}_{\text {init }}=-\left([\mathbf{R}]_{\mathrm{t}}+[\mathrm{M}]_{\mathrm{t}}+\mathrm{K}_{11^{-1}}-\left(\left(\left([\mathbf{R}]_{\mathrm{t}}+[\mathrm{M}]_{\mathrm{t}}+\mathrm{K}_{11^{-1}}\right)^{2}-4[\mathrm{M}]_{\mathrm{t}}[\mathbf{R}]_{\mathrm{t}}\right)^{1 / 2}\right)\right) \Delta \mathrm{A}_{\max }\right) /\left(2[\mathbf{R}]_{\mathrm{t}}\right)(\mathrm{Eq} \cdot 1)
$$

in which, $\mathrm{K}_{11}$ is the binding constant for $1-1$ complex formation, $[\mathrm{R}]_{\mathrm{t}}$ is the constant concentration of rhodizonate in the solution, and $[\mathrm{M}]_{\mathrm{t}}$ is the variable concentration of added metal salt.
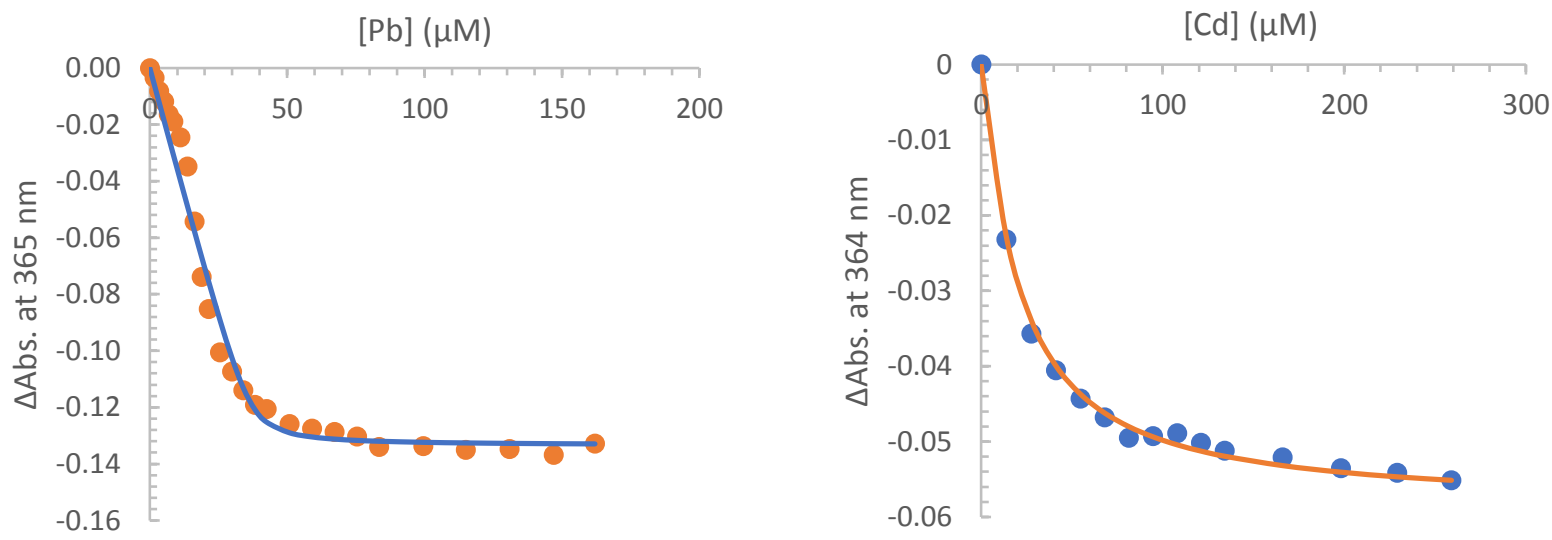

Figure S1 (left): Binding curve for the titration of a solution of $3.66 \times 10^{-5} \mathrm{M}$ of $\mathrm{Na}_{2} \mathrm{C}_{5} \mathrm{O}_{5}$ with solution of $2.50 \mathrm{x}$ $10^{-3} \mathrm{M}$ of $\mathrm{Pb}\left(\mathrm{NO}_{3}\right)_{2}$ in $3.66 \times 10^{-5} \mathrm{M}$ of $\mathrm{Na}_{2} \mathrm{C}_{5} \mathrm{O}_{5}$ in $1: 1$ water:ethanol. $\mathrm{K}_{11}=1.85 \times 10^{6} \mathrm{M}^{-1}$.

Figure S2 (right): Binding curve for the titration of a solution of $3.12 \times 10^{-5} \mathrm{M}$ of $\mathrm{Na}_{2} \mathrm{C}_{5} \mathrm{O}_{5}$ with $8.29 \times 10^{-3} \mathrm{M}^{-5}$ $\mathrm{Cd}\left(\mathrm{NO}_{3}\right)_{2} \bullet 4 \mathrm{H}_{2} \mathrm{O}$ in $3.12 \times 10^{-5} \mathrm{M}$ of $\mathrm{Na}_{2} \mathrm{C}_{5} \mathrm{O}_{5}$ in 1:1 water:ethanol. $\mathrm{K}_{11}=1.30 \times 10^{5} \mathrm{M}^{-1}$. 


\section{FT-IR Spectroscopy}

The IR spectra for the PbCroc and CdCroc complexes are shown in Figures S3 and S4, respectively.

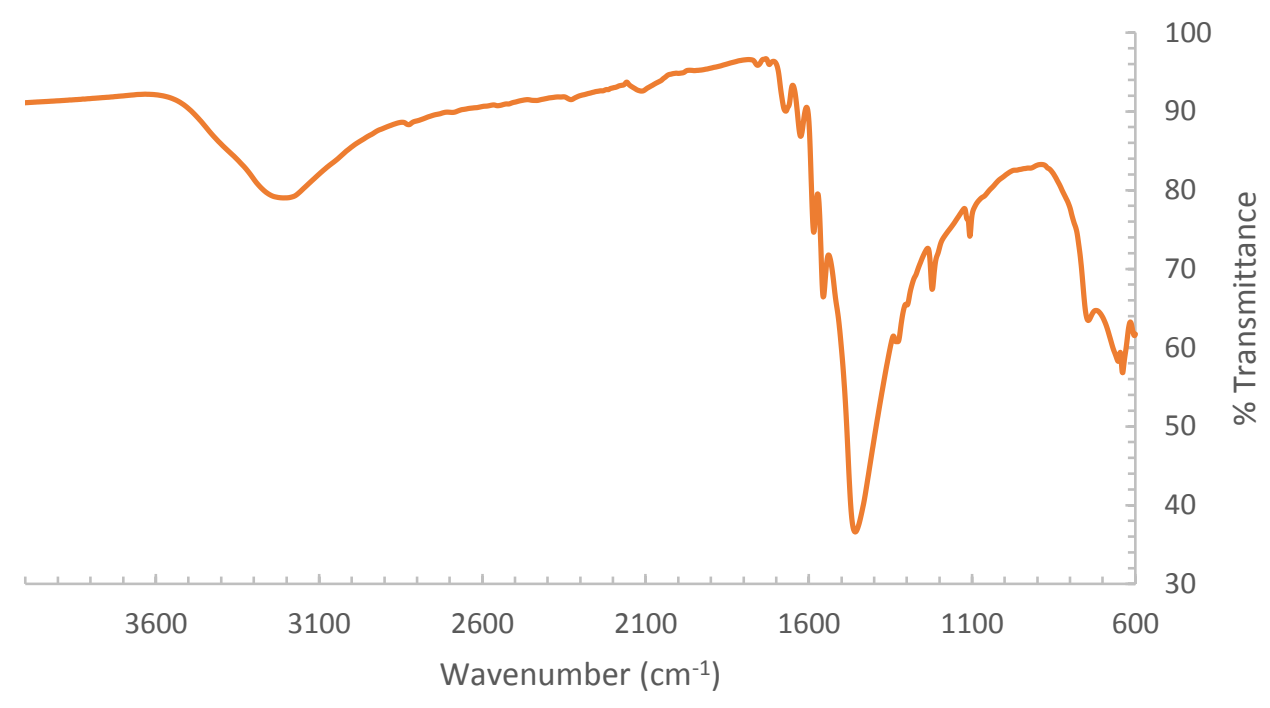

Figure S3: FT-IR spectrum of the PbCroc complex.

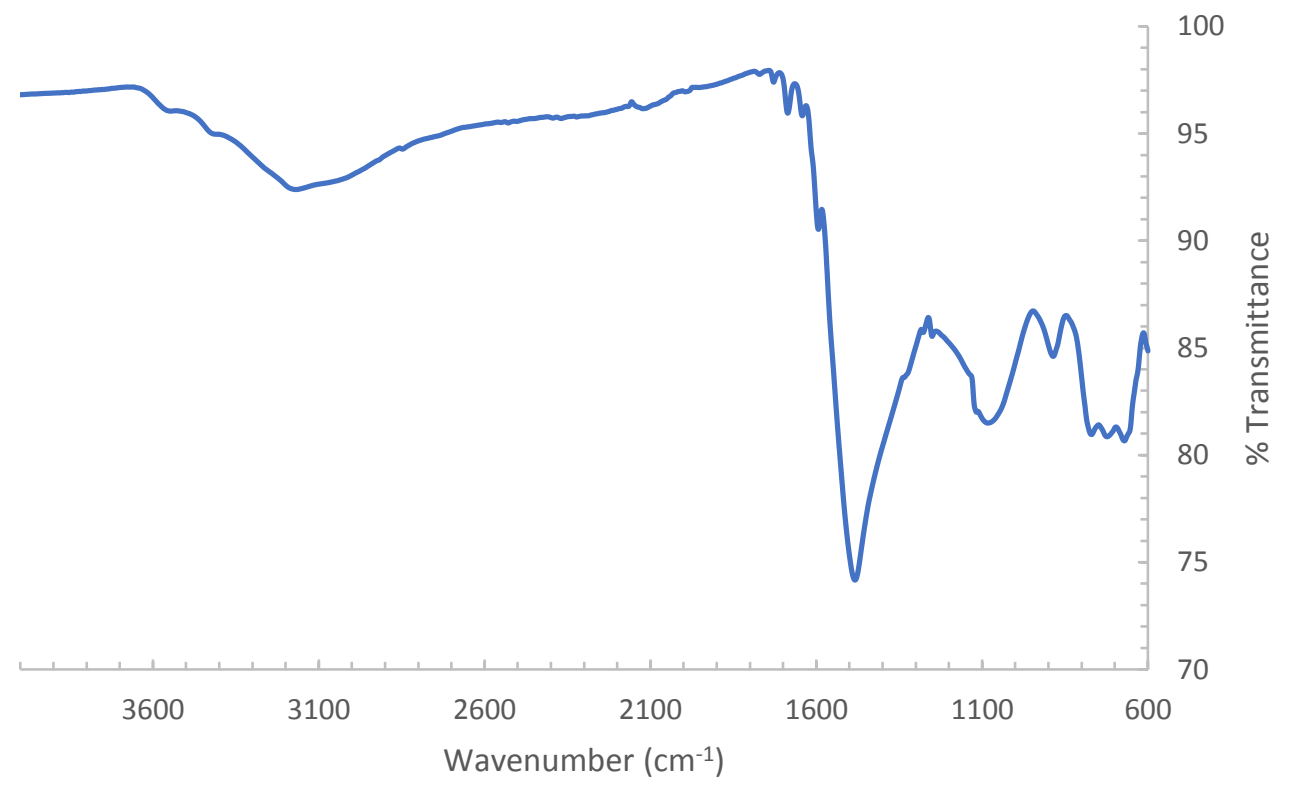

Figure S4: FT-IR spectrum of the CdCroc complex. 